\title{
A Multidrug ABC Transporter with a Taste for Salt
}

\author{
Saroj Velamakanni ${ }^{19}$, Calvin H. F. Lau ${ }^{19}$, Daniel A. P. Gutmann ${ }^{1}$, Henrietta Venter ${ }^{1}$, Nelson P. Barrera ${ }^{2}$, \\ Markus A. Seeger ${ }^{1}$, Barbara Woebking ${ }^{1}$, Dijana Matak-Vinkovic ${ }^{2}$, Lekshmy Balakrishnan ${ }^{1}$, Yao Yao ${ }^{1}$, \\ Edmond C. Y. U ${ }^{1}$, Richard A. Shilling ${ }^{1}$, Carol V. Robinson ${ }^{2}$, Peter Thorn ${ }^{1 \times}$, Hendrik W. van Veen ${ }^{1 *}$
}

1 Department of Pharmacology, University of Cambridge, Cambridge, United Kingdom, 2 Department of Chemistry, University of Cambridge, Cambridge, United Kingdom

\begin{abstract}
Background: LmrA is a multidrug ATP-binding cassette (ABC) transporter from Lactococcus lactis with no known physiological substrate, which can transport a wide range of chemotherapeutic agents and toxins from the cell. The protein can functionally replace the human homologue $A B C B 1$ (also termed multidrug resistance P-glycoprotein MDR1) in lung fibroblast cells. Even though LmrA mediates ATP-dependent transport, it can use the proton-motive force to transport substrates, such as ethidium bromide, across the membrane by a reversible, $\mathrm{H}^{+}$-dependent, secondary-active transport reaction. The mechanism and physiological context of this reaction are not known.

Methodology/Principal Findings: We examined ion transport by LmrA in electrophysiological experiments and in transport studies using radioactive ions and fluorescent ion-selective probes. Here we show that LmrA itself can transport $\mathrm{NaCl}$ by a similar secondary-active mechanism as observed for ethidium bromide, by mediating apparent $\mathrm{H}^{+}-\mathrm{Na}^{+}-\mathrm{Cl}^{-}$symport. Remarkably, LmrA activity significantly enhances survival of high-salt adapted lactococcal cells during ionic downshift.

Conclusions/Significance: The observations on $\mathrm{H}^{+}-\mathrm{Na}^{+}-\mathrm{Cl}^{-}$co-transport substantiate earlier suggestions of $\mathrm{H}^{+}$-coupled transport by LmrA, and indicate a novel link between the activity of LmrA and salt stress. Our findings demonstrate the relevance of investigations into the bioenergetics of substrate translocation by $A B C$ transporters for our understanding of fundamental mechanisms in this superfamily. This study represents the first use of electrophysiological techniques to analyze substrate transport by a purified multidrug transporter.
\end{abstract}

Citation: Velamakanni S, Lau CHF, Gutmann DAP, Venter H, Barrera NP, et al. (2009) A Multidrug ABC Transporter with a Taste for Salt. PLoS ONE 4(7): e6137. doi:10.1371/journal.pone.0006137

Editor: Maxim Antopolsky, University of Helsinki, Finland

Received March 11, 2009; Accepted May 22, 2009; Published July 10, 2009

Copyright: (c) 2009 Velamakanni et al. This is an open-access article distributed under the terms of the Creative Commons Attribution License, which permits unrestricted use, distribution, and reproduction in any medium, provided the original author and source are credited.

Funding: This research was funded by the Biotechnology and Biological Sciences Research Council (BBSRC), Medical Research Council (MRC), and Royal Society. SV is a recipient of a Cambridge Nehru Scholarship. CHFL received a research studentship of Peterhouse, Cambridge. HV is a Dorothy Hodgkin Research Fellow of the Royal Society. MS obtained fellowships from the Swiss National Foundation, the Novartis Foundation and the European Molecular Biology Organization (EMBO). The funders had no role in study design, data collection and analysis, decision to publish, or preparation of the manuscript.

Competing Interests: The authors have declared that no competing interests exist.

*E-mail: hwv20@cam.ac.uk

a Current address: Department of Biomedical Sciences, University of Queensland, Brisbane, Australia

9 These authors contributed equally to this work.

\section{Introduction}

In order to evade the toxic effects of noxious compounds, prokaryotic and eukaryotic cells have developed several resistance mechanisms. One of these mechanisms involves the active extrusion of structurally-unrelated compounds from the cell by multidrug transporters [1]. The expression of these systems is a major cause of reduced efficacy of agricultural fungicides and herbicides [2,3], and failure of chemotherapeutic treatment of tumours [4-6] and infections by pathogenic microorganisms [7]. Since the discovery of the human multidrug transporter ABCB 1 (also termed multidrug resistance P-glycoprotein MDR1) [8,9], homologues of ABCBl have been identified in a variety of microorganisms. Among these, one of the most extensively studied proteins is LmrA from the non-pathogenic bacterium Lactococcus lactis [10].

LmrA is a half-transporter that contains an N-terminal membrane domain (MD) followed by a nucleotide-binding domain (NBD). By analogy to ABCBl in which two half- transporters are fused into a single polypeptide, LmrA homodimerises to form the transport-active complex [11]. LmrA can functionally substitute for ABCB1 in human lung fibroblasts, and exhibits a substrate specificity similar to that of the human protein [12]. Its specificity is also similar to that of bacterial homologues such as HorA in Lactobacillus brevis, which is associated with resistance to iso- $\alpha$-acids (in hopped beer) at increased copy number of the horA-containing plasmid pRH45 [13,14], and the recently crystallized, genomically-encoded MsbA from Escherichia coli, Salmonella typhimurium, and Vibrio cholera [15-19] and Sav1866 from Staphylococcus aureus [20,21]. Studies on the pharmacological properties of multidrug $\mathrm{ABC}$ transporters (reviewed in $[1,19,22,23])$ revealed that the ability of these systems to transport multiple drugs is based on direct drug-protein interactions. A recent crystal structure of mouse $\mathrm{ABCB}$ la demonstrates substrate binding at the top of an internal cavity at the dimer interface between the two half-transporters near the leaflet-leaflet interface of the membrane [24], consistent with biochemical observations on MsbA [19]. 
Gram-positive lactic acid bacteria play an important role in the food industry due to their fermentative capacities [25]. L. lactis is the main component of the starter cultures used for cheese making. Its main activity during milk fermentation is the conversion of lactose to lactic acid, which results in the lowering of the $\mathrm{pH}$ in the product to prevent the growth of spoilage and pathogenic microorganisms [26]. During this process as well as in its natural habitats, L. lactis is subjected to stressful conditions which, in addition to acidity, include exposure to antibacterial peptides (e.g. bacteriocins), toxic metabolic products (e.g. bile salts and fatty acids), secondary metabolites (e.g. antibiotics), and high osmolarity/dehydration; $\mathrm{NaCl}$ is an important constituent of cheese which can reach concentrations of up to $0.5 \mathrm{M}$.

In this paper, we report that $\mathrm{LmrA}$ can mediate a $\mathrm{H}^{+}-\mathrm{Na}^{+}-\mathrm{Cl}^{-}$ symport reaction and can enhance survival of salt-adapted cells during downshifts in the extracellular ion concentration. Observations on the redundancy and overlapping drug specificities of multidrug ABC transporters [27] and the examples of regulation of their expression independent of multiple drugs [28] have indicated that some of these $\mathrm{ABC}$ transporters might have alternative or additional physiological roles. Our findings on LmrA now provide an interesting example of this notion.

\section{Results}

\section{Purified LmrA-MD and LmrA do not contain additional}

\section{binding partners}

In previous work in L. lactis, we engineered a truncated LmrA protein, termed LmrA-MD, which lacks the NBD [29]. Studies on the purified protein in proteoliposomes revealed that homodimeric LmrA-MD functions as a secondary-active multidrug translocator by catalyzing reversible ethidium-proton symport without a requirement for ATP [30]. This observation was recently extended to full-length LmrA in proteoliposomes [31]. As our observations on ion-coupled transport are the first reported for a purified multidrug $\mathrm{ABC}$ transporter, we used a recently described method involving nano-electrospray mass spectrometry [32] to confirm the subunit stoichiometry, lipid binding, and purity of our preparations of LmrA and LmrA-MD. Predominant well-resolved peaks corresponded to molecular masses of $132233 \pm 26 \mathrm{Da}$ and $80140 \pm 17 \mathrm{Da}$ and were consistent with homodimers of LmrA and LmrA-MD (Figure 1); calculated molecular masses of the dimeric complexes were 132312 and $80218 \mathrm{Da}$, respectively. Peaks corresponding to tetramers of LmrA and LmrA-MD were also observed in both spectra and are likely due to a low level of association of dimers within the micelles. Lipid binding was also evident for both proteins with masses consistent with a cardiolipin (1352 Da). Notably our protein preparations did not contain additional (membrane) proteins that could act as binding partners of LmrA or LmrA-MD.

\section{Ionic currents in LmrA-MD-containing proteoliposomes}

We studied the mechanism of ion transport by LmrA-MD in more detail. Surprisingly, when proteoliposomes containing purified and functionally reconstituted LmrA-MD were fused with a phospholipid bilayer in the tip of a glass pipette, macroscopic currents associated with thousands of LmrA-MD molecules could be recorded in response to hyper- or depolarizing pulses from a holding potential of $0 \mathrm{mV}$ (Figure 2A). The current changed linearly with voltage and showed no evidence for rectification, indicating comparable rates of ion conductance in uptake and efflux directions (Figure 2B). No significant currents could be recorded for empty control liposomes (Figure 2C) or proteoliposomes containing a mutant LmrA-MD protein in which two basic residues (K32 and R34) in the cytosolic N-terminal elbow helix are replaced by E (termed EE LmrA-MD) (Figure 2D).

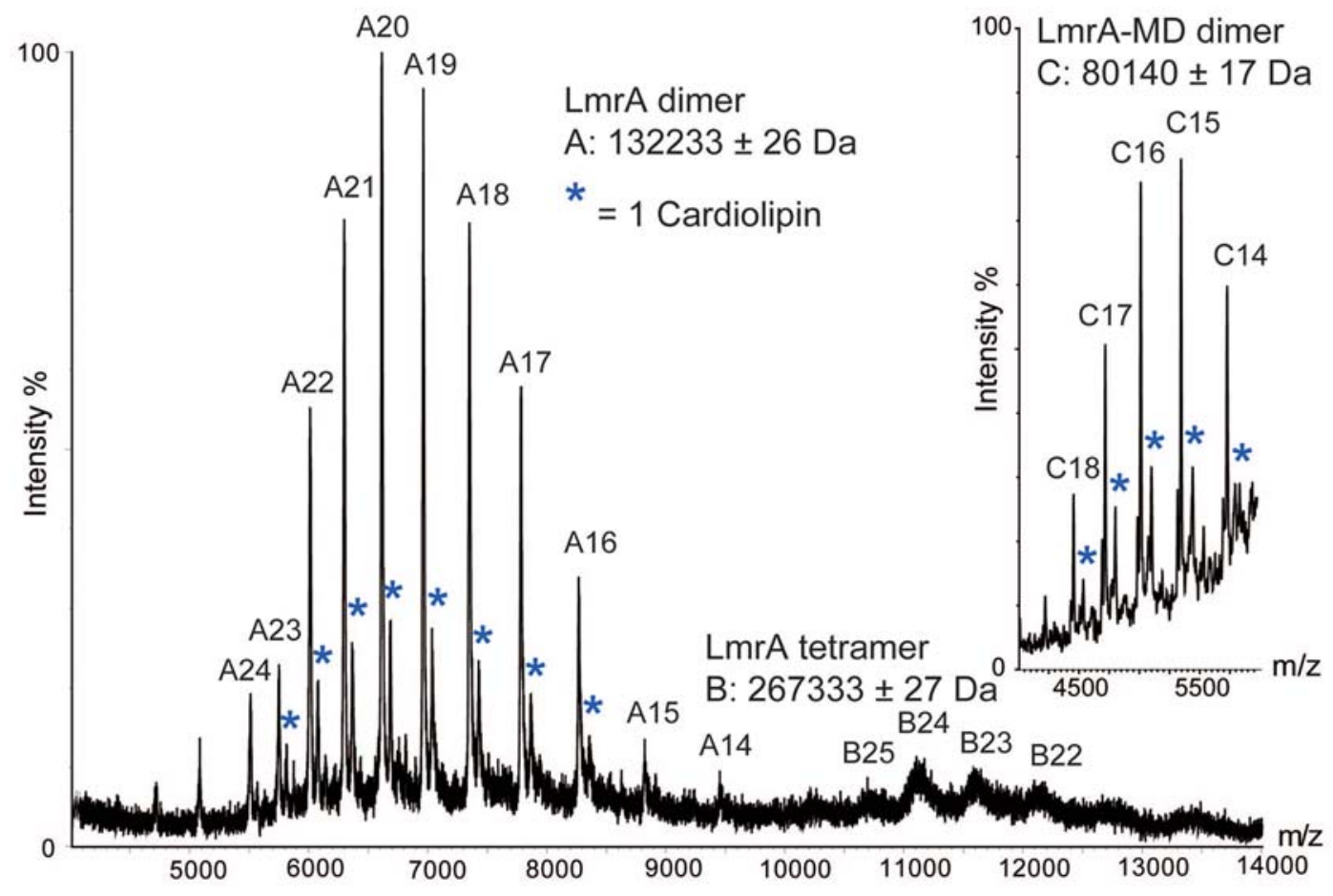

Figure 1. Mass spectra of purified LmrA and LmrA-MD showing predominant homodimer formation for both proteins. Peaks assigned to binding of one cardiolipin molecule are labelled (blue stars), and measured molecular masses are shown. doi:10.1371/journal.pone.0006137.g001 

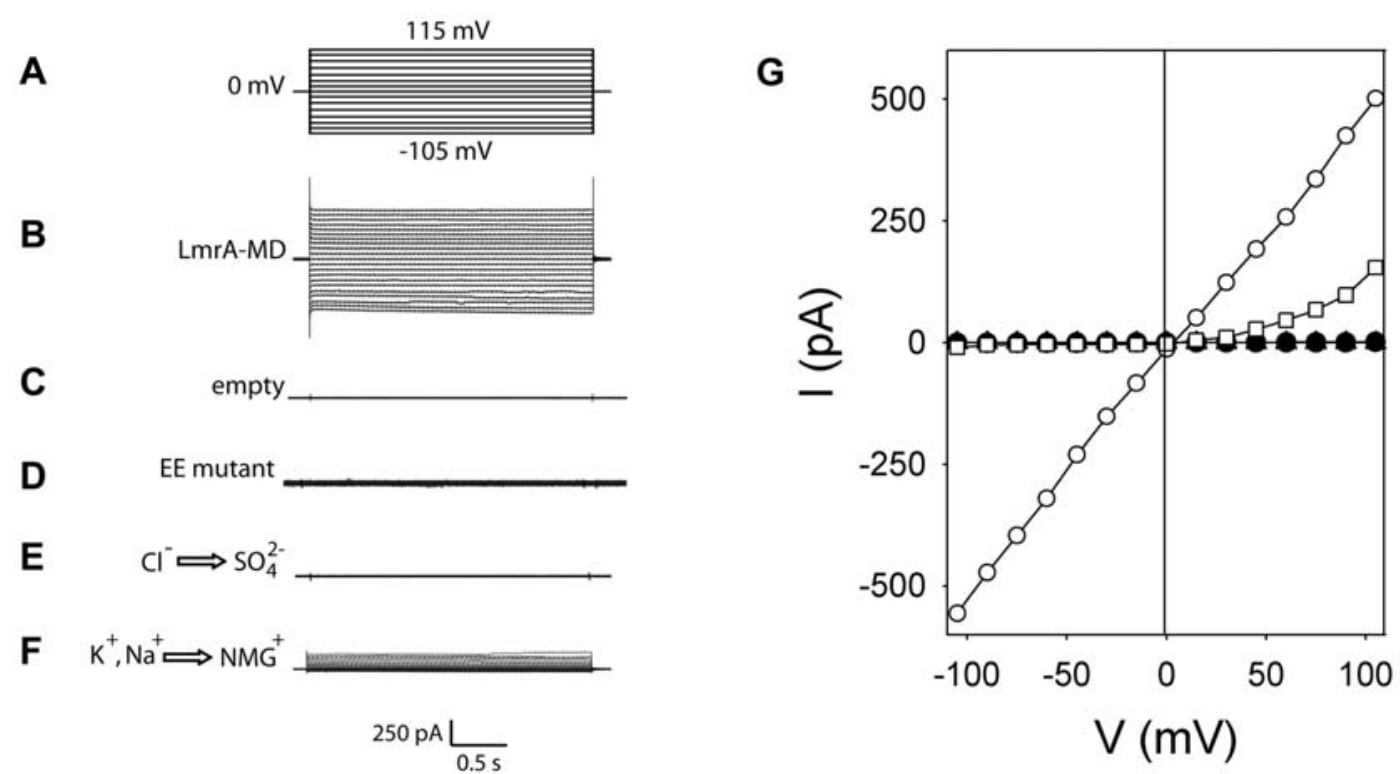

Figure 2. Electrophysiological analyses of ion transport in proteoliposomes by 'dip-tip' method. A, Voltage step protocol from a holding potential of $0 \mathrm{mV}$ to various voltages (ranging from $-105 \mathrm{mV}$ to $+115 \mathrm{mV}$ ), back to $0 \mathrm{mV}$. B, C, D, Current traces for LmrA-MD (B) or empty liposomes without protein (C) or EE LmrA-MD (D) in the presence of $10 \mathrm{mM} \mathrm{NaCl}$. E, $\mathbf{F}$, Current traces for LmrA-MD in the presence of SO${ }_{4}{ }^{2-}$ instead of $\mathrm{Cl}^{-}(\mathrm{E})$, or $\mathrm{NMG}^{+}$instead of $\mathrm{Na}^{+}$and $\mathrm{K}^{+}(\mathrm{F})$. G, I-V curves from the traces in (B-F) $\left(\bigcirc, \mathrm{LmrA}^{-M D}\right.$; $\bullet$, replacement of $\mathrm{Cl}^{-}$by $\mathrm{SO}_{4}{ }^{2-}$; $\square$, replacement of $\mathrm{K}^{+} / \mathrm{Na}^{+}$by $\mathrm{NMG}^{+} ; \nabla$, EE; $\triangle$, empty liposomes; the latter two traces are hidden behind $\left.\bullet\right)$. $(n=15)$ doi:10.1371/journal.pone.0006137.g002

This mutant was equally well expressed in cells as wildtype. In addition, the mutation did not alter ethidium and Hoechst 33342 binding by purified LmrA-MD or LmrA in detergent solution, or the basal ATPase activity of the latter, suggesting that no gross conformational changes were introduced (data not shown). Currents were also absent upon the replacement of $\mathrm{Cl}^{-}$in the internal and external bath solutions by $\mathrm{SO}_{4}{ }^{2-}$, and were strongly reduced by the replacement of $\mathrm{K}^{+}$and $\mathrm{Na}^{+}$by N-methyl-Dglucosamine $^{+}\left(\mathrm{NMG}^{+}\right)$(Figure $\left.2 \mathrm{E}-\mathrm{G}\right)$, demonstrating that the currents are a result of LmrA-MD mediated $\mathrm{Cl}^{-}$and $\mathrm{Na}^{+}$and/or $\mathrm{K}^{+}$transport.

\section{Proton-coupled chloride transport}

The transport of $\mathrm{Cl}^{-}$in LmrA-MD-containing proteoliposomes was further studied in transport assays using radioactive ${ }^{36} \mathrm{Cl}^{-}$. Upon the imposition of a transmembrane potential $(\Delta \psi)$ of $-120 \mathrm{mV}$ (inside negative), proteoliposomes accumulated ${ }^{36} \mathrm{Cl}^{-}$ about 17.4-fold above the equilibration level obtained for empty liposomes $\left(\left[\mathrm{Cl}^{-}\right]_{\text {in }}=2.79 \pm 0.07 \mathrm{mM}\right.$ for $\mathrm{LmrA}-\mathrm{MD}$ versus $0.16 \pm 0.04 \mathrm{mM}$ for control) (Figure 3A). In contrast, ${ }^{36} \mathrm{Cl}^{-}$ transport by the EE LmrA-MD was strongly reduced and almost identical to levels in empty liposomes. The accumulation of $\mathrm{Cl}^{-}$by wildtype LmrA-MD at the negative side of the proteoliposomal membrane points to the electrogenic co-transport of $\mathrm{Cl}^{-}$and cations.

One type of cation that is co-transported with $\mathrm{Cl}^{-}$is $\mathrm{H}^{+}$. The imposition of a transmembrane chemical proton gradient $(-\mathrm{Z} \Delta \mathrm{pH}$, interior alkaline) of $-49 \mathrm{mV}$ in proteoliposomes by the outward diffusion on acetic acid $\left(\mathrm{pH} 7.6_{\text {in }} / \mathrm{pH} 6.8_{\text {out }}\right.$ ) [29] (Figure 3B) was accompanied by a 4.2 -fold accumulation of ${ }^{36} \mathrm{Cl}^{-}$above the equilibration level in empty liposomes $\left(\left[\mathrm{Cl}^{-}\right]_{\text {in }}=1.61 \pm 0.12 \mathrm{mM}\right.$ for LmrA-MD versus $0.38 \pm 0.08 \mathrm{mM}$ for control). Uptake by $\mathrm{EE}$ LmrA-MD was comparable to control. The addition of an uncoupler that dissipated the imposed $\Delta \mathrm{pH}$ initiated efflux of previously accumulated ${ }^{36} \mathrm{Cl}^{-}$, providing evidence for concentra- tive ion uptake by LmrA-MD (Figure 3B). The uphill movement of $\mathrm{Cl}^{-}$against a concentration gradient at the expense of $\mathrm{H}^{+}$moving downhill is consistent with the notion that LmrA-MD act as a transporter. The uptake of ${ }^{36} \mathrm{Cl}^{-}$was also observed when a $\Delta \mathrm{pH}$ (interior alkaline) was imposed by $\mathrm{pH}$ jump $\left(\mathrm{pH} 7.6_{\text {in }} / \mathrm{pH} 6.8_{\text {out }}\right.$ ), but not upon imposition of a reversed $\Delta \mathrm{pH}\left(\mathrm{pH} 6.8_{\text {in }} / \mathrm{pH} 7.6_{\text {out }}\right.$ ) by this method (data not shown). Previous findings on ethidiumproton co-transport by LmrA-MD and LmrA indicated that the E314A substitution in transmembrane helix 6 abrogates $\Delta \mathrm{pH}$ dependence but not $\Delta \psi$-dependence of this reaction [29,30]. In agreement with this, the E314A mutation strongly inhibited the $\Delta \mathrm{pH}$-dependent transport of ${ }^{36} \mathrm{Cl}^{-}$, whereas the $\Delta \psi$-mediated transport was unaffected (Figure $3 \mathrm{~A}-\mathrm{B}$ ).

The observations for LmrA-MD were also relevant for fulllength $\mathrm{LmrA}$, as $\Delta \mathrm{pH}\left(\mathrm{pH} 7.6_{\text {in }} / \mathrm{pH} 6.8_{\text {out }}\right)$-driven uptake of ${ }^{36} \mathrm{Cl}^{-}$resulted in a 4.4-fold accumulation of the ion in proteoliposomes containing LmrA compared to empty liposomes $\left(\left[\mathrm{Cl}^{-}\right]_{\text {in }}=1.54 \pm 0.20 \mathrm{mM}\right.$ for $\mathrm{LmrA}$ versus $0.35 \pm 0.08 \mathrm{mM}$ for control) (Figure 3C). The $\Delta \mathrm{pH}$ (interior alkaline)-dependent uptake of $\mathrm{Cl}^{-}$could also be detected when $\mathrm{a} \mathrm{Cl}^{-}$-sensitive fluorophore was trapped in the liposomal lumen (Figure 3D). The accumulation of $\mathrm{Cl}^{-}$was observed as a fluorescence quenching with an initial rate of $(46.2 \pm 0.9) \times 10^{-3}$ a.u./s in LmrA-containing proteoliposomes versus $(13.2 \pm 7.6) \times 10^{-3}$ a.u./s in empty liposomes. Upon the addition of the $\mathrm{Cl}^{-} / \mathrm{OH}^{-}$ion exchanger tributylin chloride (TBT-Cl) to the liposomes in the presence of the $\Delta \mathrm{pH}$, a similar quenching of fluorescence was obtained as that associated with LmrA activity (Figure 3D), supporting the notion that LmrA mediates chloride-proton co-transport. Measurement of the rate of $\Delta \mathrm{pH}$-dependent ${ }^{36} \mathrm{Cl}^{-}$transport by $\mathrm{LmrA}$ as a function of the $\mathrm{Cl}^{-}$concentration indicated a high apparent affinity (Michaelis constant, $\mathrm{K}_{\mathrm{m}}$ ) of $17.9 \pm 3.7 \mu \mathrm{M} \mathrm{Cl}^{-}$and a maximum transport rate $\left(\mathrm{V}_{\max }\right)$ of about $142 \mathrm{nmol} / \mathrm{min} / \mathrm{mg}$ protein (Figure 3E). This $\mathrm{V}_{\max }$ is comparable to the maximum ATPase activity of purified LmrA (about $150 \mathrm{nmol} / \mathrm{min} / \mathrm{mg}$ 
A

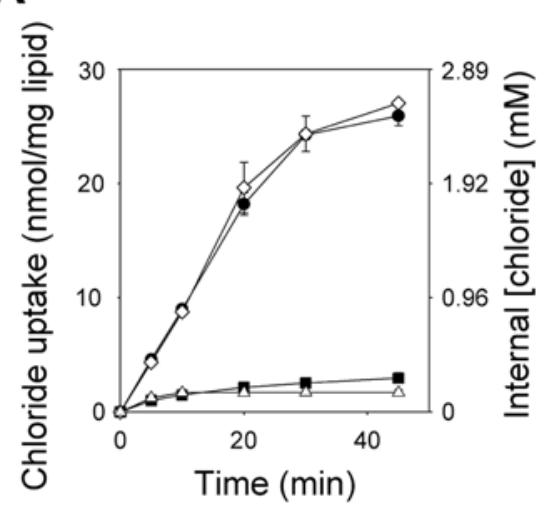

D

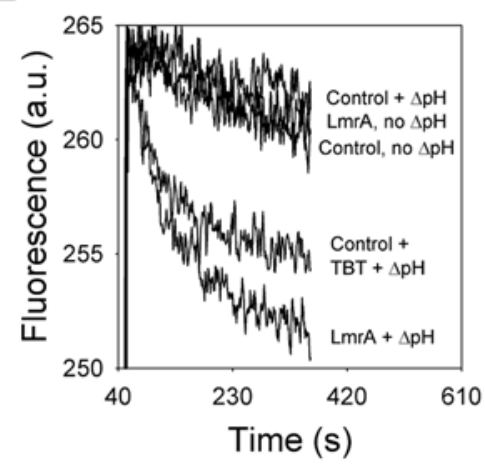

G

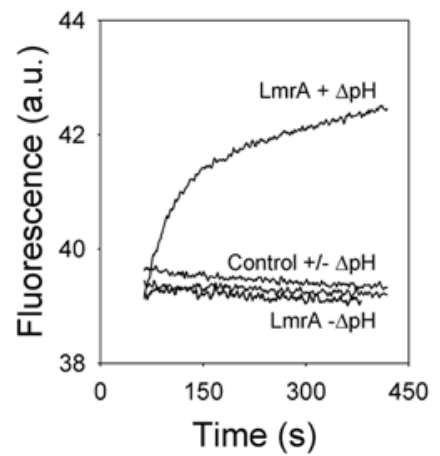

B

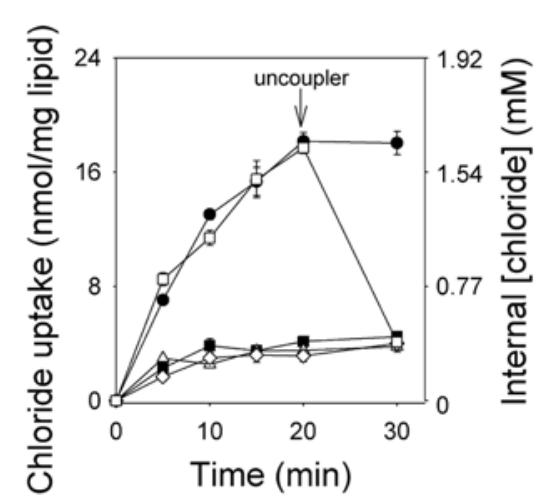

E

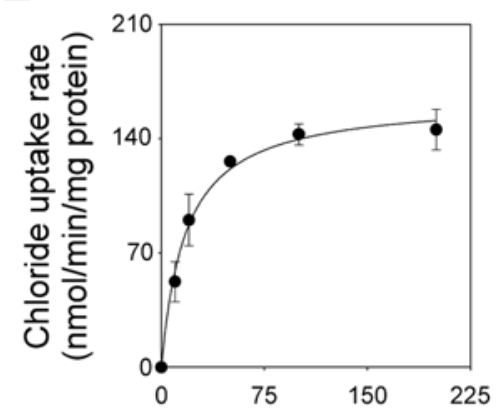

Chloride concentration $(\mu \mathrm{M})$

H

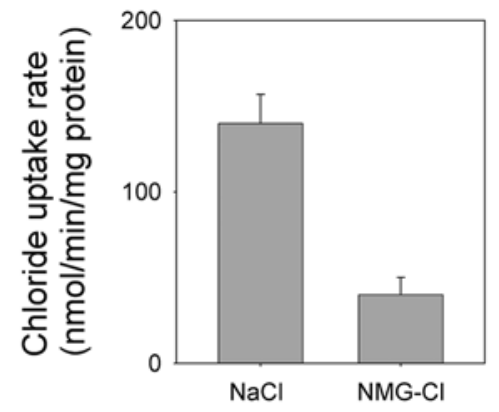

C

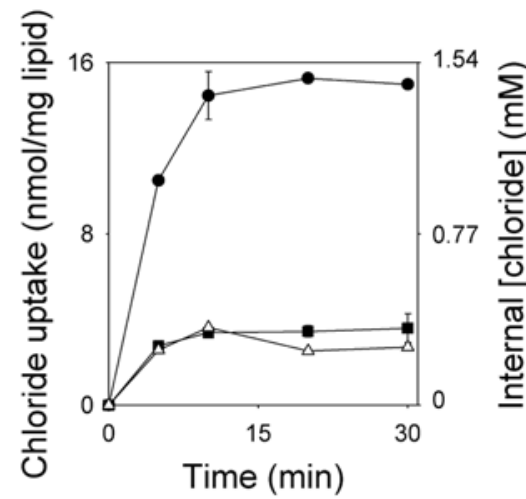

$\mathbf{F}$

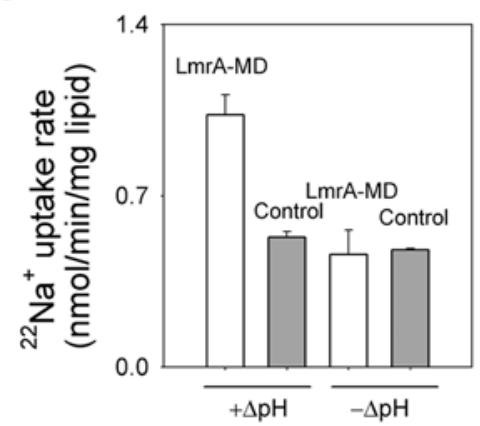

I

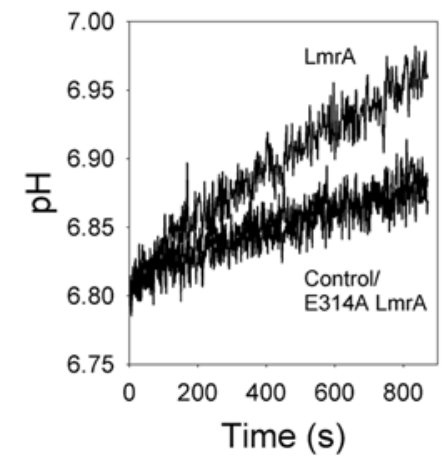

Figure 3. Ion-coupled transport in proteoliposomes. A, B, ${ }^{36} \mathrm{Cl}^{-}$uptake $(100 \mu \mathrm{M})$ by $\mathrm{LmrA}-\mathrm{MD}(\bullet), \mathrm{E} 314 \mathrm{~A} \operatorname{LmrA-MD}(\diamond)$, EE $\operatorname{LmrA}-\mathrm{MD}(\mathbf{\square})$ or empty liposomes $(\triangle)$ in the presence of a $\Delta \psi$ (interior negative) of $-120 \mathrm{mV}(\mathrm{A})$ or $-\mathrm{Z} \Delta \mathrm{pH}$ (interior alkaline) of $-49 \mathrm{mV}(\mathrm{B})$. In the duplicate experiment for LmrA-MD ( $\square$ ) in (B), the addition of uncoupler (valinomycin plus nigericin, $1 \mu \mathrm{M}$ each) at the arrow resulted in efflux of accumulated ${ }^{36} \mathrm{Cl}^{-}$, indicating concentrative uptake of the ion. $\mathbf{C}, \Delta \mathrm{pH}$ (interior alkaline)-dependent ${ }^{36} \mathrm{Cl}^{-}$uptake by $\mathrm{LmrA}(\mathbf{\bullet}), \mathrm{EE} \mathrm{LmrA}(\boldsymbol{\square})$ or empty liposomes $(\triangle)$. D, $\Delta \mathrm{pH}$ (interior alkaline)-dependent uptake of non-radioactive $\mathrm{Cl}^{-}(1 \mathrm{mM})$ by $\mathrm{LmrA}^{-}$is observed as a quench in the fluorescence of the SPQ fluorophore trapped in the lumen of the proteoliposomes. Quenching was also observed in empty liposomes (control) in the presence of the $\mathrm{Cl}^{-} /$ $\mathrm{OH}^{-}$antiporter TBT-Cl $(1 \mu \mathrm{M})$. E, Kinetic analysis of $\Delta \mathrm{pH}$ (interior alkaline)-dependent ${ }^{36} \mathrm{Cl}^{-}$uptake by $\mathrm{LmrA} . \mathbf{F}, \Delta \mathrm{pH}$ (interior alkaline)-dependent uptake of ${ }^{22} \mathrm{Na}(25 \mu \mathrm{M})$ by LmrA-MD. G, Uptake of unlabelled $\mathrm{Na}^{+}(10 \mathrm{mM})$ by $\mathrm{LmrA}$ was detected as an increase in the fluorescence of the membrane-impermeable sodium green probe trapped in the lumen. $\mathbf{H}, \mathrm{Na}^{+}(100 \mu \mathrm{M})$ stimulates the $\Delta \mathrm{pH}$-dependent uptake of ${ }^{36} \mathrm{Cl}^{-}(100 \mu \mathrm{M})$ by LmrA compared to control containing $99 \mu \mathrm{M} \mathrm{NMG}^{+}$plus $1 \mu \mathrm{M} \mathrm{Na}{ }^{+}$. I, $\mathrm{H}^{+}$efflux in proteoliposomes loaded with pH probe BCECF in the presence of an outwardly directed $\mathrm{NaCl}$ gradient. Control, empty liposomes. $(n=5)$

doi:10.1371/journal.pone.0006137.g003

protein) obtained at saturating concentrations of $\mathrm{Mg}$-ATP (above $6 \mathrm{mM}$ ) [31]. The rates of $\mathrm{Cl}^{-}$transport obtained for the EE and E314A mutants were too low to allow a reliable determination of kinetic parameters.

At steady state in Figure 2A-C, the outwardly directed chemical $\mathrm{Cl}^{-}$gradient is in equilibrium with the inwardly directed $\Delta \psi$ and
$\Delta \mathrm{pH} \quad\left(Z \log \left[\mathrm{Cl}^{-}\right]_{\text {in }} /\left[\mathrm{Cl}^{-}\right]_{\text {out }}=-(n \Delta \psi-m \mathrm{Z} \Delta \mathrm{pH}) \quad\right.$ in $\quad$ which $z=59 \mathrm{mV}$ ). From the data, $n$ was calculated as $0.7 \pm 0.1$ (Figure 3A), and $m=0.8 \pm 0.1$ (Figure $3 \mathrm{~B}$ ) and $0.8 \pm 0.2$ (Figure 3C). These estimates indicate an apparent net stoichiometry of $2(+) / \mathrm{Cl}^{-}$anion and $1 \mathrm{H}^{+} / \mathrm{Cl}^{-}$, respectively, pointing to electrogenic symport of $1 \mathrm{X}^{+}: 1 \mathrm{Cl}^{-}: 1 \mathrm{H}^{+}$. 


\section{Coupled transport of $\mathrm{NaCl}$ and protons}

Consistent with the electrophysiology experiments showing $\mathrm{Na}^{+}$/ $\mathrm{K}^{+}$conductance by LmrA-MD, $\mathrm{Na}^{+}$can participate in the $\mathrm{X}^{+}-\mathrm{Cl}^{-}$$\mathrm{H}^{+}$co-transport reaction. Upon the imposition of a $\Delta \mathrm{pH}\left(\mathrm{pH} 7.6_{\text {in }} /\right.$ $\left.\mathrm{pH} 6.8_{\text {out }}\right),{ }^{22} \mathrm{Na}^{+}$uptake in proteoliposomes containing LmrA-MD was observed above the equilibration level in empty liposomes consistent with sodium-proton co-transport (Figure 3F). The $\Delta \mathrm{pH}-$ dependent accumulation of $\mathrm{Na}^{+}$could also be monitored in $\mathrm{LmrA}$ containing proteoliposomes loaded with a $\mathrm{Na}^{+}$-sensitive fluorophore (Figure 3G). In both types of experiments, $\mathrm{LmrA}(-\mathrm{MD})$-mediated $\mathrm{Na}^{+}$transport was strongly reduced in the absence of the $\Delta \mathrm{pH}$ and identical to levels in empty liposomes. In agreement with $\mathrm{H}^{+}-\mathrm{Na}^{+}$$\mathrm{Cl}^{-}$co-transport, the presence of $\mathrm{Na}^{+}$stimulated the $\Delta \mathrm{pH}-$ dependent uptake of ${ }^{36} \mathrm{Cl}^{-}$in LmrA-containing proteoliposomes compared to a control in which the $\mathrm{Na}^{+}$concentration was reduced 100 -fold by replacement with $\mathrm{NMG}^{+}$(Figure $3 \mathrm{H}$ ). In analogous experiments with the radioactive $\mathrm{K}^{+}$analog ${ }^{86} \mathrm{Rb}^{+}$, no $\Delta \mathrm{pH}-$ dependent accumulation was observed in LmrA-MD containing proteoliposomes above control (data not shown), which most likely reflects the low affinity of $\mathrm{LmrA}-\mathrm{MD}$ for $\mathrm{K}^{+}$relative to $\mathrm{Na}^{+}$.

As the $\Delta \mathrm{pH}$ can drive $\mathrm{Na}^{+}$and $\mathrm{Cl}^{-}$transport by $\mathrm{LmrA}$, downhill transport of these ions by LmrA might be able to regenerate this $\Delta \mathrm{pH}$. To test this hypothesis, (proteo)liposomes were prepared containing a $\mathrm{pH}$-sensitive fluorophore. When the (proteo)liposomes were diluted to create an outwardly directed $\mathrm{NaCl}$ concentration gradient $\left(5 \mathrm{mM}_{\text {in }} / 0.05 \mathrm{mM}_{\text {out }}\right)$ the simultaneous efflux of $\mathrm{Na}^{+}, \mathrm{Cl}^{-}$and protons by LmrA was observed as an increase in luminal $\mathrm{pH}$ of $(15.1 \pm 1.1) \times 10^{-3}$ units/min (Figure 3I). The enhanced proton efflux was not observed for empty control liposomes or proteoliposomes containing E314A LmrA $(\mathrm{pH}$ increase of $(5.2 \pm 1.0) \times 10^{-3}$ versus $(6.2 \pm 1.3) \times 10^{-3}$ units $/ \mathrm{min}$, respectively). No differences in the luminal $\mathrm{pH}$ were observed upon dilution without the imposition of the $\mathrm{NaCl}$ gradient (data not shown).

\section{Ion transport in intact cells}

The addition of glucose as a source of metabolic energy to cells pre-equilibrated with $100 \mu \mathrm{M} \mathrm{Na}{ }^{36} \mathrm{Cl}$ elicited ${ }^{36} \mathrm{Cl}^{-}$efflux by LmrA but not by an ATPase-deficient LmrA mutant in which the catalytic K388 residue in the Walker A region of the NBD was deleted ( $\Delta$ K 388 ) [31] (Figure 4A). Efflux was also not observed for non-expressing control cells or cells expressing EE LmrA. The notion that LmrA can transport salt in an ATP-dependent fashion is supported by the inorganic ion-dependent stimulation of the
A

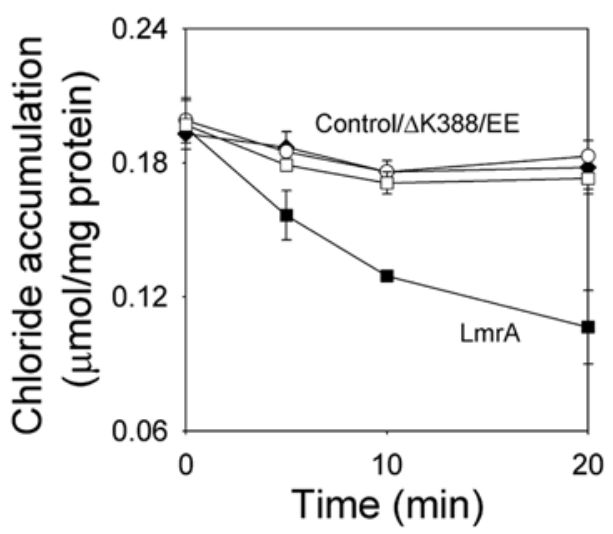

C

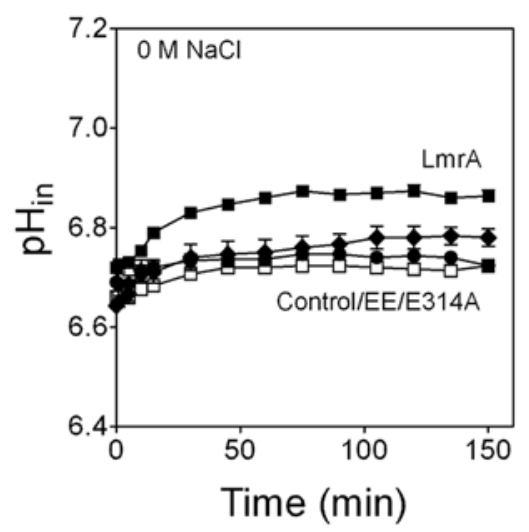

D

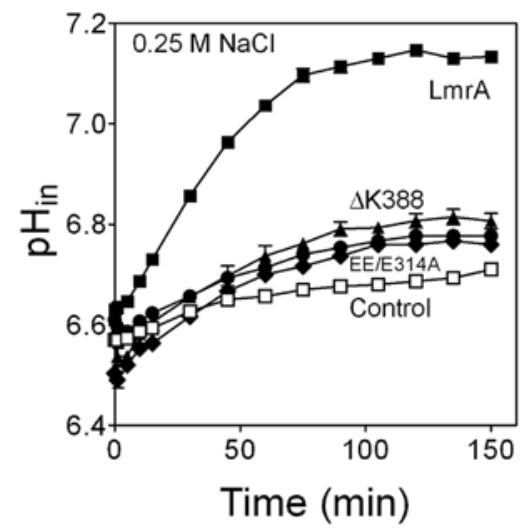

B

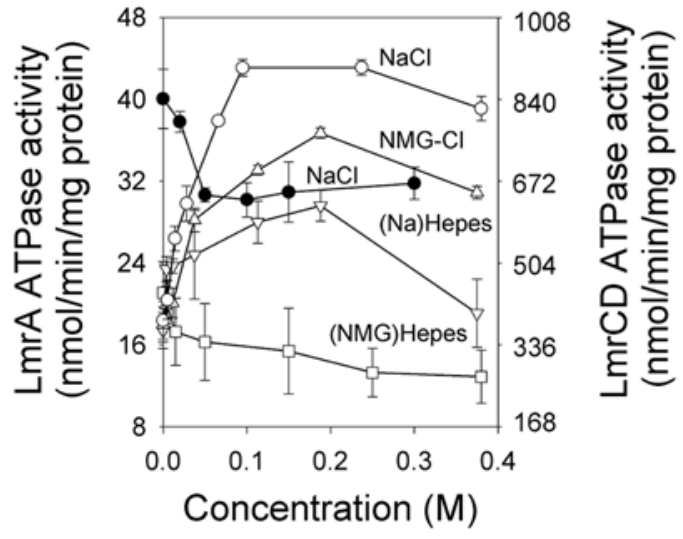

E

Figure 4. Ion transport in intact cells. A, $\mathrm{Cl}^{-}$efflux in cells preloaded with $\mathrm{Na}^{36} \mathrm{Cl}(100 \mu \mathrm{M})$ upon the addition of glucose ( $\mathbf{\square}$, LmrA; $\square$, nonexpressing control; $\mathrm{EE} \mathrm{LmrA;} \bigcirc, \triangle \mathrm{K} 388 \mathrm{LmrA}$ ). B, Effect of the concentration of $\mathrm{Na}^{+}, \mathrm{NMG}^{+}$or $\mathrm{Cl}^{-}$on the ATPase activity of purified LmrA (open symbols) or LmrCD (-) measured at $2 \mathrm{mM} \mathrm{Mg-ATP.} \mathrm{C,D,E,} \mathrm{H}^{+}$efflux in energized cells, loaded with pH probe CFDASE to monitor the intracellular pH $\left(\mathrm{pH}_{\text {in }}\right)$ in the absence (C) or presence of (D) $0.25 \mathrm{M} \mathrm{NaCl}$ or (E) $0.672 \mathrm{M}$ sucrose in the external buffer (each equivalent to $\left.521 \mathrm{mOsm}\right)(\mathbf{\square}, \mathrm{LmrA} ; \square$, non-expressing control;, $\mathrm{EE} \mathrm{LmrA} ; \bullet, \mathrm{E} 314 \mathrm{~A} \mathrm{LmrA} ; \boldsymbol{\Lambda}, \Delta \mathrm{K} 388 \mathrm{LmrA})$. Metabolic energy was generated in the cells by the addition of $20 \mathrm{mM}$ glucose (at $\mathrm{t}=0 \mathrm{~min}$ in the figures), $15 \mathrm{~min}$ after the addition of the $\mathrm{NaCl}$ or sucrose or solvent control. $(n=8)$

doi:10.1371/journal.pone.0006137.g004 
basal ATPase activity of the protein in detergent solution (Figure 4B). A maximal stimulation was observed for $\mathrm{NaCl}$, whereas an intermediate level of stimulation was obtained for (Na)Hepes and (NMG)Cl. On the other hand, (NMG)Hepes did not affect the basal ATPase activity suggesting that the iondependent stimulation of the LmrA-ATPase activity is due to a specific interaction with $\mathrm{Na}^{+}$and $\mathrm{Cl}^{-}$. This notion is also supported by the observation that, in contrast to LmrA, the ATPase activity of the purified multidrug ABC transporter LmrCD from L. lactis [33] is not stimulated by $\mathrm{NaCl}$ up to a concentration of $0.3 \mathrm{M}$ (Figure $4 \mathrm{~B}$ ).

$\mathrm{H}^{+}-\mathrm{Na}^{+}-\mathrm{Cl}^{-}$co-transport by $\mathrm{LmrA}$ was also indicated in $\mathrm{H}^{+}$ efflux measurement from cells. Estimation of the intracellular $\mathrm{pH}$ in the cells with a fluorescent $\mathrm{pH}$ indicator revealed an alkalinization of the cytosol in LmrA expressing cells, consistent with $\mathrm{H}^{+}$efflux by LmrA (Figure 4G). The external $\mathrm{pH}$ was constant during the time course of these experiments (not shown). Interestingly, the addition of $0.25 \mathrm{M} \mathrm{NaCl}$ to the extracellular buffer did not have an immediate effect on alkalinization, but strongly stimulated proton efflux after a prolonged exposure of the cells for $15 \mathrm{~min}$ (Figure 4D). This time dependence suggests that the $\mathrm{H}^{+}-\mathrm{Na}^{+}-\mathrm{Cl}^{-}$co-transport reaction is enhanced by elevated concentrations of $\mathrm{NaCl}$ in the cytosol. $\mathrm{NaCl}$ could, to a limited extend, be replaced by $\mathrm{KCl}$ at a similar osmolality (521 mOsm) (not shown) but could not be replaced by sucrose (Figure $4 \mathrm{E}$ ), indicating an ionic requirement in the stimulation. The E314A, EE and $\Delta \mathrm{K} 388$ mutations in LmrA strongly reduced the elevation of the cytosolic $\mathrm{pH}$ in the presence of $\mathrm{NaCl}$ (Figure 4D), consistent with their inhibition of LmrAmediated ion transport (Figure 3-4A).

\section{LmrA activity enhances cell survival}

A relationship was found between LmrA activity and cell viability during ionic downshift. When cells were pre-exposed to $100 \mathrm{mM} \mathrm{NaCl}$ plus $0.5 \mathrm{M}$ sucrose for $30 \mathrm{~min}$, and subsequently diluted 100-fold in ultra pure $\mathrm{H}_{2} \mathrm{O}$, the cells expressing $\mathrm{LmrA}$ survived the downshock with a significant gain of viability compared to the non-expressing control (Figure 5A). Cell survival required exposure to $\mathrm{NaCl}$, which could partially be substituted by $\mathrm{KCl}$ and $\mathrm{Na}_{2} \mathrm{SO}_{4}$, but not by sucrose only (Figure $5 \mathrm{~A}$ ). These data are consistent with the stimulatory effect of these salts, but not of sucrose, on LmrA-mediated $\mathrm{H}^{+}$efflux (Figure 4D). In contrast, no differences in cell survival between LmrA expressing cells and control cells were observed following a minor 4-fold downshock (Figure 5A). The survival of $\mathrm{NaCl}$ adapted cells was strongly reduced for the $\mathrm{EE}$ and $\Delta \mathrm{K} 388$ mutants (Figure $5 \mathrm{~B}$ ), which are impaired in ion transport (Figure 2-4), indicating that LmrA itself can diminish irreversible damage in salt-exposed cells during the ionic downshock.

\section{Discussion}

Collectively, the observations on proton-coupled $\mathrm{Cl}^{-}$transport, proton-coupled $\mathrm{Na}^{+}$transport, $\mathrm{Na}^{+}$-dependent $\mathrm{Cl}^{-}$transport, and $\mathrm{NaCl}$-coupled proton transport by purified protein in proteoliposomes (Figure 3) provide compelling evidence that both LmrA$\mathrm{MD}$ and $\mathrm{LmrA}$ can mediate an electrogenic $\mathrm{H}^{+}-\mathrm{Na}^{+}-\mathrm{Cl}^{-}$symport reaction. An alternative explanation in which $\mathrm{LmrA}-\mathrm{MD} / \mathrm{LmrA}$ might regulate the activity of an unidentified, associated membrane protein appears less likely since an associated protein was not observed in our purified protein preparations in analyses based on silver-stained SDS-PAAGE, N-terminal amino acid sequencing (data not shown) and non-dissociating mass spectrometry (Figure 1). Consistent with previous cross-linking experiments on LmrA and LmrA-MD [11,29], and studies demonstrating that

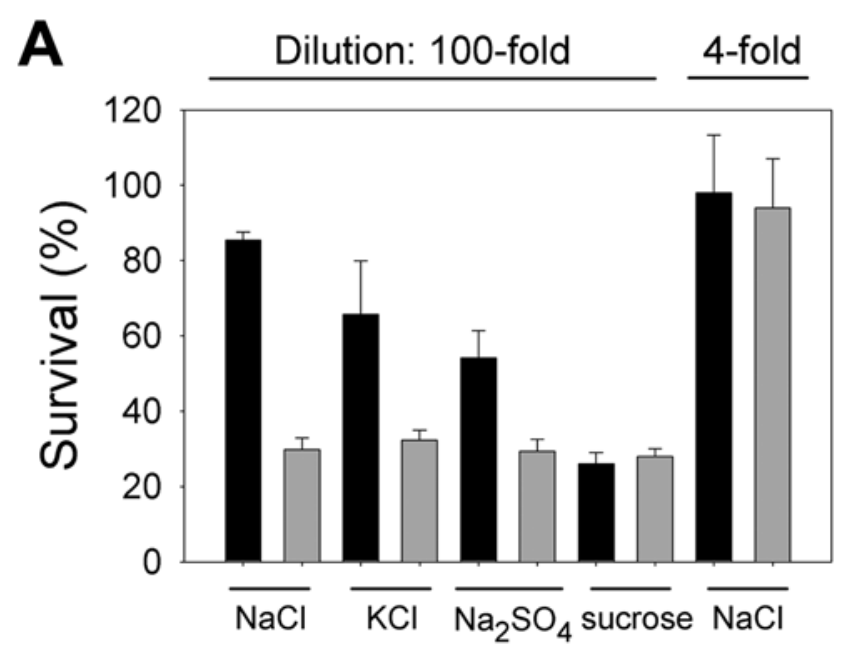

B

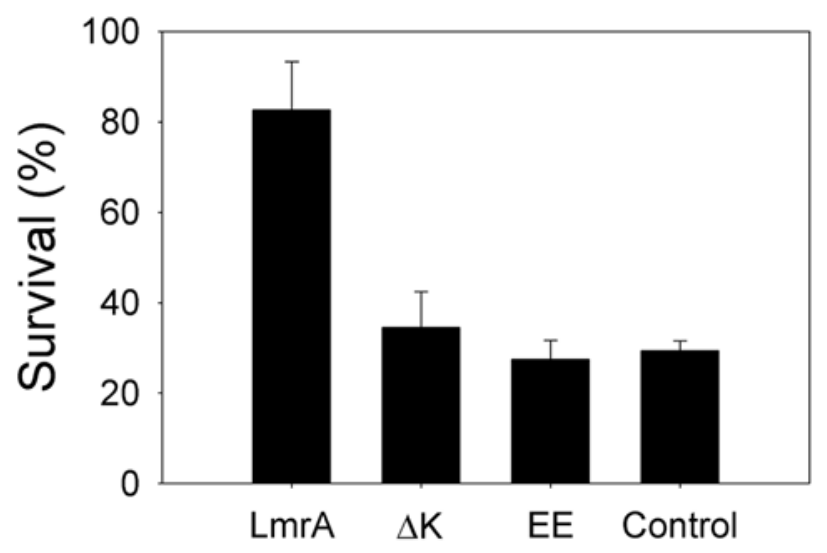

Figure 5. LmrA activity enhances cell survival. A, Viability of energized cells (solid bar, LmrA; grey bar, non-expressing control) adapted for $30 \mathrm{~min}$ in buffer containing $0.5 \mathrm{M}$ sucrose without or with $100 \mathrm{mM} \mathrm{NaCl}, 100 \mathrm{mM} \mathrm{KCl}$ or $50 \mathrm{mM} \mathrm{Na}_{2} \mathrm{SO}_{4}$, followed by 100 -fold dilution into ultrapure water, or in buffer containing $0.125 \mathrm{M}$ sucrose and $25 \mathrm{mM} \mathrm{NaCl}$ (control referred to as 4-fold dilution). B, Effect of mutations in LmrA on the viability after dilution of cells pre-exposed to $100 \mathrm{mM} \mathrm{NaCl}$ plus $0.5 \mathrm{M}$ sucrose under conditions as in $(\mathrm{A}) .(n=10)$ doi:10.1371/journal.pone.0006137.g005

(i) an inactive LmrA mutant exhibits negative dominance over an active wild-type LmrA protein in a co-reconstituted liposomal system, and (ii) the covalent fusion of two wild-type LmrA monomers yields a functional transporter whereas the fusion of a wild-type monomer and the inactive mutant monomer does not [11], the mass spectra (Figure 1) showed predominant peaks for the LmrA and LmrA-MD dimers, and showed no evidence for other proteinacious binding partners. Ion transport was strongly inhibited by the distinct EE and E314A mutations in the MD, and Walker A $\Delta \mathrm{K} 388$ mutation in the NBD (Figure 2-4) the latter of which significantly reduces the LmrA ATPase activity down to $4 \%$ of wildtype level $[31,34]$. Taken together, the data suggest that $\mathrm{LmrA} / \mathrm{LmrA}-\mathrm{MD}$ itself is responsible for inorganic ion transport.

Current advancements in the biochemistry and structural biology of $\mathrm{ABC}$ transporters indicate that these systems operate by a mechanism in which binding sites in the MDs for transport substrate(s) are alternately exposed to the inside and outside surface of the membrane in response to the ATP-driven dimerization of NBDs and their dissociation following ATP 
hydrolysis (for reviews, see Ref. 35, 36). The strong inhibition by the $\Delta \mathrm{K} 388$ mutation of LmrA-mediated $\mathrm{Cl}^{-}$and $\mathrm{H}^{+}$efflux from ATP-containing cells (Fig. 4A-D) is consistent with this notion, and suggests that substrate $\left(\mathrm{H}^{+}, \mathrm{Na}^{+}\right.$and $\left.\mathrm{Cl}^{-}\right)$efflux is dependent on phosphate-bond energy derived from ATP hydrolysis. Evidence for ATP-dependence of transport by LmrA was also previously obtained in drug transport studies [10,11,31,37]. However, electrochemical ion gradient-dependent $\mathrm{H}^{+}-\mathrm{Na}^{+}-\mathrm{Cl}^{-}$ symport by LmrA in proteoliposomes in the absence of ATP implies that this reaction can occur in the absence of a catalytic cycle at the NBDs; indeed, the same reaction can be detected for LmrA-MD that does not contain the NBD. Hence, in the absence of the successful dimerization of NBDs and/or their conformational coupling in the LmrA transporter, the MDs operate in a reversible, secondary-active mode in which the direction of transport is dictated by the orientation and magnitude of the electrochemical substrate $\left(\mathrm{H}^{+}, \mathrm{Na}^{+}\right.$and $\left.\mathrm{Cl}^{-}\right)$gradients. It is interesting to note that for the LmrA homologue Sav1866, which exhibits a similar reversibility of transport as LmrA [21], the homodimer was co-crystallized with a $\mathrm{Na}^{+}$ion bound in the hinge region connecting the $\alpha$-helical and $\beta$-sheet subdomains in each NBD [20], where these ions might affect the dimerisation of NBDs and/or their conformational coupling to MDs. Ion sensing in LmrA might also occur by the cytosolic N-terminal elbow helix which is predicted to be in close proximity to the inside surface of the membrane [20]. In LmrA, this helix contains 8 basic residues (R10, K14, K18, K22, K26, R29, K32, R34) which could bind anions $\left(\mathrm{Cl}^{-}\right)$and which, in competition with cations $\left(\mathrm{Na}^{+}\right)$, could interact with acidic lipids and/or neighbouring residues in transmembrane helix 2,3 and 6. Consequently, the interactions at the elbow helix might occur in an ionic strength ( $\mathrm{NaCl}$ )dependent manner. The phenotype of the EE mutant (Figure 2-5) suggests that the simultaneous replacement of K32 and R34 by E in the elbow helix interferes with its function. Hence, iondependent regulatory mechanisms might exist in this type of multidrug $\mathrm{ABC}$ exporter that affect transport activity.

LmrA shares its ability to conduct $\mathrm{Cl}^{-}$(Figure 2) with the only established $\mathrm{ABC} \mathrm{Cl}{ }^{-}$channel CFTR [38], in which ATP binding triggers channel opening and ATP hydrolysis triggers channel closing through the effect of nucleotide binding/hydrolysis on NBD dimerisation [39]. In addition, LmrA might share its ability to conduct $\mathrm{Cl}^{-}$with human $\mathrm{ABCB} 1$, the expression of which was reported to be associated with a $\mathrm{Cl}^{-}$dependent regulation of intracellular $\mathrm{pH}$ in chinese hamster ovary fibroblasts [40,41] and with volume-dependent $\mathrm{Cl}^{-}$currents in mouse fibroblasts [42]. Whereas ABCBl was suggested to act as a $\mathrm{Cl}^{-}$channel [42], our data on LmrA-mediated, proton-motive force (interior negative and alkaline)-dependent accumulation of $\mathrm{Cl}^{-}$in proteoliposomes (Figure 3A-D) and the release of pre-accumulated $\mathrm{Cl}^{-}$from proteoliposomes upon dissipation of the proton-motive force by protonophore (Figure 3B) indicate that LmrA operates as a proton-coupled $\mathrm{Cl}^{-}$transporter. Recently, members of the Chloride Channel (ClC) family were shown to mediate a rapid $2 \mathrm{Cl}^{-} / \mathrm{H}^{+}$antiport reaction, indicating a close connection between transporters and channels in this protein family [43-46]. As LmrA and CFTR are structurally related proteins, our findings on LmrA-mediated $\mathrm{Cl}^{-}$transport might point to a mechanistic relationship between transporters and channels in the $\mathrm{ABC}$ superfamily.

The observations on salt transport by LmrA and the increased survival of salt-adapted LmrA-expressing cells during ionic downshift (Figure 5) imply a novel link between LmrA activity and the homeostatic control of the intracellular $\mathrm{pH}$ and $\mathrm{NaCl}$ concentration, and represent an interesting example of the notion that multidrug $\mathrm{ABC}$ transporters can have physiological roles that go beyond the transport of toxic compounds. We found that LmrA expression does not confer resistance on lactococcal cells to $\mathrm{NaCl}$ or acidity during exponential growth (data not shown) where ion homeostasis is in place. Therefore, the beneficial action of LmrA on cell survival appears to be relevant during periods of disturbed ionic balance. It should be mentioned that the deletion mutant lacking the $\operatorname{mrA}$ gene did not reveal a significant growth or survival phenotype compared to the wildtype background in $L$. lactis NZ9000 (data not shown) suggesting insufficient expression of genomic $\operatorname{lm} r \mathrm{~A}$ under laboratory conditions in M17 medium, or a redundancy in LmrA function as was observed for mechanosensitive channel proteins in E. coli $[47,48]$. The MS data (Figure 1) indicate binding of a specific lipid, cardiolipin, by the LmrA dimer. As it was previously proposed that LmrA might act as a flippase for hydrophobic compounds including lipid $[11,12,49]$, the potential role of lipid transport by LmrA in cell membrane homeostasis during salt stress (including the regulation of lipid composition, membrane tension and/or surface area) remains to be determined.

\section{Materials and Methods}

\section{Cell and membrane preparations}

The expression of LmrA, LmrA-MD, LmrA(-MD) mutants, and LmrCD in the drug-hypersensitive L. lactis strain NZ9000 $\Delta l m r A$ $\Delta \operatorname{lmr} C D[31,33]$, the solubilization and affinity-purification of these proteins in $n$-dodecyl $\beta$-D-maltoside (DDM, Anatrace)-containing solutions, and the reconstitution of purified proteins at a proteinlipid ratio of 1:100 (w/w) in Triton X-100 (BDH Chemicals)destabilized proteoliposomes (with an internal volume of $10.4 \mu \mathrm{l} /$ $\mathrm{mg}$ lipid) in $50 \mathrm{mM} \mathrm{KPi}$ (pH 7.6), $2 \mathrm{mM} \mathrm{MgSO}_{4}$ was performed by methods as described previously [21,29,32,49]. For mass spectrometry of LmrA, protein was purified as above using dodecyl octa(ethylene oxide) (C12E8, Anatrace) rather than DDM at equivalent $\mathrm{w} / \mathrm{v}$ concentration. To determine the ATPase activity of LmrA, protein was solubilized in C12E8 and bound to $\mathrm{Ni}^{2+}$-nitrilotriacetic acid (Ni-NTA) resin as above, and subsequently washed and eluted with buffer containing $0.1 \%(\mathrm{w} / \mathrm{v})$ foscholine-12 (Anatrace).

\section{Genetic manipulations}

Site directed mutagenesis was performed on pGHLmrA [30] using the QuikChange kit (Stratagene). The K32E/R34E (EE) double mutant was generated with primers $5^{\prime}$ - GCA GAA CCA GAG TAT CTG TTT TTT GTG ATT G $-3^{\prime}$ and $5^{\prime}$-TAG TCT GGT TCT GCT GCA CGA ATT AAT TTG-3'. To generate EE LmrA-MD, the coding region for the MD [29] was PCR amplified using the mutant $\operatorname{lm} r A$ gene as a template.

\section{Mass spectrometry}

Analyses were performed using a nanoflow ES mass spectrometer Q-ToF2 (Micromass), which has been modified for transmission and detection of ions at high $\mathrm{m} / \mathrm{z}$ ratios [50]. Aliquots of complex-containing solutions $(2 \mu \mathrm{L}$ at $\sim 10 \mu \mathrm{M}$ concentration in $190 \mu \mathrm{M}$ C12E8) were introduced via gold-coated nanoflow electrospray capillaries, prepared in-house. The following experimental parameters were used to record mass spectra of $1 \mathrm{mg} / \mathrm{ml}$ LmrA and LmrA-MD: needle voltage of $1.8 \mathrm{kV}$ and MCP $2350 \mathrm{~V}, 150 \mathrm{~V}$ cone and $100 \mathrm{~V}$ collision voltages for LmrA-MD and $200 \mathrm{~V}$ both cone and collision voltages for LmrA.

\section{Electrophysiological measurements}

Ion conductance was measured by the 'dip-tip' technique [51]. The external bath and the tip of a micropipette were filled with 
$10 \mathrm{mM}(\mathrm{K})$ Hepes (pH 7.4), $1 \mathrm{mM} \mathrm{MgCl}_{2}, 2 \mathrm{mM} \mathrm{CaCl} 2,1 \mathrm{mM}$ $\mathrm{KCl}$ and $10 \mathrm{mM} \mathrm{NaCl}$. A planar lipid bilayer in the tip of the pipette was formed using 1-palmitoyl-2-oleyl-sn-glycero-3-phosphocholine and 1,2-dioleoyl-sn-glycero-3-phosphoethanolamine (Avanti Polar lipids) in a ratio of 7:3 (w/w), which increased the resistance of the pipette from about $7 \mathrm{M} \Omega$ to about $75 \mathrm{G} \Omega$. Proteoliposomes prepared from synthetic lipids fused with the planar lipid bilayer following their addition to the external bath at a concentration of $19 \mu \mathrm{g}$ protein $/ \mathrm{ml}$.

\section{Biochemical assays}

The transport of radioactive chloride or sodium ions was measured by rapid filtration after 100-fold dilution in $50 \mathrm{mM} \mathrm{KPi}$ (pH 6.8), $2 \mathrm{mM} \mathrm{MgSO}$, or buffers and conditions as described [52], containing $100 \mu \mathrm{M} \mathrm{Na}{ }^{36} \mathrm{Cl}(16 \mathrm{mCi} / \mathrm{g})$ (MP Biomedicals) or $25 \mu \mathrm{M}{ }^{22} \mathrm{NaCl}(100 \mathrm{mCi} / \mathrm{mg}$ ) (Amersham Biosciences). The transport of $\mathrm{H}^{+}$in proteoliposomes in $5 \mathrm{mM} \mathrm{KPi}(\mathrm{pH} \mathrm{7.6)}$ or non-radioactive $\mathrm{Cl}^{-}(1 \mathrm{mM})$ or $\mathrm{Na}^{+}(10 \mathrm{mM})$ was measured by

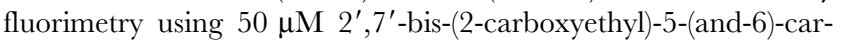
boxyfluorescein (BCECF) [29], $300 \mu \mathrm{M}$ 6-methoxy-N-(3-sulfopropyl) quinolinium (SPQ), or $1 \mathrm{mM}$ membrane-impermeable sodium green (Molecular Probes), respectively, that was trapped in the lumen. Cells in phosphate-buffered saline were loaded with $30 \mu \mathrm{M}$ 5(6)-carboxyfluorescein diacetate succinimidyl ester (CFDASE) (Molecular Probes) for detection of $\mathrm{H}^{+}$transport [53], and washed and resuspended in $50 \mathrm{mM} \mathrm{KPi} \mathrm{(pH} \mathrm{6.0).}$ Fluorescence was calibrated in the presence of nigericin $\left(\mathrm{pH}_{\mathrm{in}}=\mathrm{pH}_{\text {out }}\right)$ using a micro $\mathrm{pH}$ electrode for measurement of $\mathrm{pH}_{\text {out }}$. ATPase activities on purified protein $(1 \mu \mathrm{g}$ in $30 \mu \mathrm{l}$ buffer $)$ were estimated by the malachite green method as described [31] using LmrCD in $0.05 \%$ (w/v) DDM or LmrA in $0.1 \%(\mathrm{w} / \mathrm{v})$ foscholine-12.

\section{References}

1. Higgins CF (2007) Multiple molecular mechanisms for multidrug resistance transporters. Nature 446: 749-757.

2. Klein M, Burla B, Martinoia E (2006) The multidrug resistance-associated protein (MRP/ABCC) subfamily of ATP-binding cassette transporters in plants. FEBS Lett 580: 1112-1122.

3. de Waard MA, Andrade AC, Hayashi K, Schoonbeek HJ, Stergiopoulos I, et al. (2006) Impact of fungal drug transporters on fungicide sensitivity, multidrug resistance and virulence. Pest Manag Sci 62: 195-207.

4. Leslie EM, Deeley RG, Cole SP (2001) Toxicological relevance of the multidrug resistance protein 1, MRP1 (ABCC1) and related transporters. Toxicology 167: 3-23.

5. Borst P, Elferink RO (2002) Mammalian ABC transporters in health and disease. Annu Rev Biochem 71: 537-592.

6. Gottesman MM, Fojo T, Bates SE (2002) Multidrug resistance in cancer: role of ATP-dependent transporters. Nat Rev Cancer 2: 48-58.

7. Webber MA, Piddock LJ (2003) The importance of efflux pumps in bacterial antibiotic resistance. J Antimicrob Chemother 51: 9-11.

8. Juliano RL, Ling V (1976) A surface glycoprotein modulating drug permeability in Chinese hamster ovary cell mutants. Biochim Biophys Acta 455: 152-162.

9. Ueda K, Cardarelli C, Gottesman MM, Pastan I (1987) Expression of a fulllength cDNA for the human MDR1 gene confers resistance to colchicine, doxorubicin, and vinblastine. Proc Natl Acad Sci USA 84: 3004-3008.

10. van Veen HW, Venema K, Bolhuis H, Oussenko I, Kok J, et al. (1996) Multidrug resistance mediated by a bacterial homolog of the human multidrug transporter MDR1. Proc Natl Acad Sci USA 93: 10668-10672.

11. van Veen HW, Margolles A, Muller M, Higgins CF, Konings WN (2000) The homodimeric ATP-binding cassette transporter LmrA mediates multidrug transport by an alternating two-site (two-cylinder engine) mechanism. EMBO J 19: 2503-2514.

12. van Veen HW, Callaghan R, Soceneantu L, Sardini A, Konings WN, et al. (1998) A bacterial antibiotic-resistance gene that complements the human multidrug-resistance P-glycoprotein gene. Nature 391: 291-295.

13. Sami M, Suzuki K, Sakamoto K, Kadokura H, Kitamoto K, et al. (1998) A plasmid pRH45 of Lactobacillus brevis confers hop resistance. J Gen Appl Microbiol 44: 361-363.

\section{Cell viability}

Cell suspensions $\left(\mathrm{OD}_{660}=0.5\right)$ were pre-incubated for $30 \mathrm{~min}$ in $50 \mathrm{mM}$ (NMG)Hepes (pH 7.4) plus $20 \mathrm{mM}$ glucose with additions as indicated in the legend to Figure $5 \mathrm{~A}-\mathrm{B}$ after which they were 100-fold diluted into ultra pure water. After $10 \mathrm{~min}$, cells were diluted $10^{6}$-fold and $0.1 \mathrm{ml}$ was plated onto M17 agar plates supplemented with $5 \mu \mathrm{g} / \mathrm{ml}$ chloramphenicol and $0.5 \%$ (w/ v) glucose. The plates were incubated overnight at $30^{\circ} \mathrm{C}$ and the number of colony forming units (cfu)/plate was counted. The $100 \%$ value refers to $\mathrm{cfu} /$ plate immediately prior to the dilution of the cells in water, and was equal to 48 and 45 for LmrA-expressing and control cells, respectively.

\section{Data analysis}

All statistical analyses were performed using the paired Student's $t$-test with a 95\% confidence interval for the sample mean, based on $n$ independent observations with different cell batches or (proteo)liposome preparations.

\section{Acknowledgments}

We are grateful to Clemens Glaubitz, Peter McNaughton, Ruth MurrellLagnado and Lesley MacVinish for interesting discussions. HWvV also thanks present and past members of the lab for excellent input during the 6 years of experimental work underlying this paper. Romola Davenport and John Banfield from the Department of Plant Sciences, University of Cambridge, are acknowledged for assistance with the ${ }^{22} \mathrm{Na}^{+}$transport measurements.

\section{Author Contributions}

Conceived and designed the experiments: SV CHL DAG HV NPB MAS BW DMV LB YY ECU RAS GVR PT HWVV. Performed the experiments: SV CHL DAG HV NPB MAS BW DMV LB YY ECU RAS. Analyzed the data: SV CHL DAG HV NPB MAS BW DMV LB YY EGU RAS GVR PT HWvV. Contributed reagents/materials/analysis tools: CVR PT HWvV. Wrote the paper: HWvV.

14. Sakamoto K, Margolles A, van Veen HW, Konings WN (2001) Hop resistance in the beer spoilage bacterium Lactobacillus brevis is mediated by the ATP-binding cassette multidrug transporter HorA. J Bacteriol 183: 5371-5375.

15. Reuter G, Janvilisri T, Venter H, Shahi S, Balakrishnan L, et al. (2003) The ATP binding cassette multidrug transporter LmrA and lipid transporter MsbA have overlapping substrate specificities. J Biol Chem 278: 35193-35198.

16. Woebking B, Reuter G, Shilling RA, Velamakanni S, Shahi S, et al. (2005) Drug-lipid A interactions on the Escherichia coli ABC transporter MsbA. J Bacteriol 187: 6363-6369.

17. Ward A, Reyes CL, Yu J, Roth CB, Chang G (2007) Flexibility in the ABC transporter MsbA: Alternating access with a twist. Proc Natl Acad Sci USA 104: 19005-19010.

18. Eckford PD, Sharom FJ (2008) Functional characterization of Escherichia coli MsbA: interaction with nucleotides and substrates. J Biol Chem 283: $12840-12850$.

19. Woebking B, Velamakanni S, Federici L, Seeger MA, Murakami S, et al. (2008) Functional role of transmembrane helix 6 in drug binding and transport by the ABC transporter MsbA. Biochemistry 47: 10904-10914.

20. Dawson RJ, Locher KP (2006) Structure of a bacterial multidrug ABC transporter. Nature 443: 180-185.

21. Velamakanni S, Yao Y, Gutmann DA, van Veen HW (2008) Multidrug transport by the ABC transporter Sav1866 from Staphylococcus aureus. Biochemistry 47: 9300-9308.

22. Ambudkar S, Dey S, Hrycyna CA, Ramachandra M, Pastan I, et al. (1999) Biochemical, cellular, and pharmacological aspects of the multidrug transporter. Annu Rev Pharmacol Toxicol 39: 361-398.

23. Shilling RA, Venter H, Velamakanni S, Bapna A, Woebking B, et al. (2006) New light on multidrug binding by an ATP-binding-cassette transporter. Trends Pharmacol Sci 27: 195-203.

24. Aller SG, Yu J, Ward A, Weng Y, Chittaboina S, et al. (2009) Structure of Pglycoprotein reveals a molecular basis for poly-specific drug binding. Science 323: $1718-1722$.

25. Makarova K, Slesarev A, Wolf Y, Sorokin A, Mirkin B, et al. (2006) Comparative genomics of the lactic acid bacteria. Proc Natl Acad Sci USA 103: $15611-15616$ 
26. McKay LL, Baldwin KA (1990) Applications for biotechnology: present and future improvements in lactic acid bacteria. FEMS Microbiol Rev 87: 3-14.

27. Borges-Walmsley MI, McKeegan KS, Walmsley AR (2003) Structure and function of efflux pumps that confer resistance to drugs. Biochem $\mathrm{J} 376$ : 313-338.

28. Kolaczkowska A, Kolaczkowski M, Goffeau A, Moye-Rowley WS (2008) Compensatory activation of the multidrug transporters Pdr5p, Snq2p, and Yorlp by Pdrlp in Saccharomyces cerevisiae. FEBS Lett 582: 977-983.

29. Venter H, Shilling RA, Velamakanni S, Balakrishnan L, van Veen HW (2003) An ABC transporter with a secondary-active multidrug translocator domain. Nature 426: 866-870.

30. Shilling RA, Federici L, Walas F, Venter H, Velamakanni S, et al. (2005) A critical role of a carboxylate in proton conduction by the ATP-binding cassette multidrug transporter LmrA. FASEB J 19: 1698-1700.

31. Venter H, Velamakanni S, Balakrishnan L, van Veen HW (2008) On the energy-dependence of Hoechst 33342 transport by the ABC transporter LmrA. Biochem Pharmacol 75: 866-874.

32. Barrera NP, Isaacson SC, Zhou M, Bavro VN, Welch A, et al. (2009) Mass spectrometry of membrane transporters reveals subunit stoichiometry and interactions. Nature Methods, Advance Online Publication; doi:10.1038/ nmeth. 1347

33. Lubelski J, de Jong A, van Merkerk R, Agustiandari H, Kuipers OP, et al. (2006) $\mathrm{LmrCD}$ is a major multidrug resistance transporter in Lactococcus lactis. Mol Microbiol 61: 771-781.

34. Hellmich UA, Haase W, Velamakanni S, van Veen HW, Glaubitz C (2008) Caught in the act: ATP hydrolysis of an ABC-multidrug transporter followed by real-time magic angle spinning NMR. FEBS Lett 582: 3557-3562.

35. Oldham ML, Davidson AL, Chen J (2008) Structural insights into ABC transporter mechanism. Curr Opin Struct Biol 18: 726-733.

36. Seeger MA, van Veen HW (2009) Molecular basis of multidrug transport by ABC transporters. Biochim Biophys Acta 1794: 725-737.

37. Balakrishnan L, Venter H, Shilling RA, van Veen HW (2003) Reversible transport by the ATP-binding cassette multidrug export pump LmrA: ATP synthesis at the expense of downhill ethidium uptake. J Biol Chem 279: $11273-11280$

38. Riordan JR, Chang XB (1992) CFTR, a channel with the structure of a transporter. Biochim Biophys Acta 1101: 221-222.

39. Gadsby DC, Vergani P, Csanády L (2006) The ABC protein turned chloride channel whose failure causes cystic fibrosis. Nature 440: 477-483.
40. Roepe PD, Weisburg JH, Luz JG, Hoffman MM, Wei LY (1994) Novel Cl- dependent intracellular $\mathrm{pH}$ regulation in murine MDR1 transfectants and potential implications. Biochemistry 33: 11008-11015.

41. Hoffman MM, Roepe PD (1999) Analysis of ion transport perturbations caused by hu MDR1 protein overexpression. Biochemistry 36: 11153-11168.

42. Valverde MA, Díaz M, Sepúlveda FV, Gill DR, Hyde SC, et al. (1992) Volumeregulated chloride channels associated with the human multidrug-resistance Pglycoprotein. Nature 355: 830-833.

43. Accardi A, Miller C (2004) Secondary active transport mediated by a prokaryotic homologue of $\mathrm{ClC} \mathrm{Cl}^{-}$channels. Nature 427: 803-807.

44. Dutzler R (2006) The ClC family of chloride channels and transporters. Curr Opin Struct Biol 16: 439-446.

45. Scheel O, Zdebik AA, Lourdel S, Jentsch TJ (2005) Voltage-dependent electrogenic chloride/proton exchange by endosomal CLC proteins. Nature 436: 424-427.

46. Picollo A, Pusch M (2005) Chloride/proton antiporter activity of mammalian CLC proteins ClC-4 and ClC-5. Nature 436: 420-423.

47. Sukharev SI, Blount P, Martinac B, Kung C (1997) Mechanosensitive channels of Escherichia coli: The MscL gene, protein and activities. Annu Rev Physiol 59: 633-657.

48. Levina N, Tötemeyer S, Stokes NR, Louis P, Jones MA, et al. (1999) Protection of Escherichia coli cells against extreme turgor by activation of $\mathrm{MscS}$ and $\mathrm{MscL}$ mechanosensitive channels: identification of genes required for $\mathrm{MscS}$ activity. EMBO J 18: 1730-1737.

49. Margolles A, Putman M, van Veen HW, Konings WN (1999) The purified and functionally reconstituted multidrug transporter LmrA of Lactococcus lactis mediates the transbilayer movement of specific fluorescent phospholipids. Biochemistry 38: 16298-16306.

50. Sobott F, Hernández H, McCammon MG, Tito MA, Robinson GV (2002) A tandem mass spectrometer for improved transmission and analysis of large macromolecular assemblies. Anal Chem 74: 1402-1407.

51. Thrower EC (1999) Measurement of Ca2+ flux through $\operatorname{Ins}(1,4,5) \mathrm{P} 3$ receptor$\mathrm{Ca}^{2+}$ channels in lipid bilayers ("dip-tip" and "Schindler" methodology). Methods Mol Biol 114: 221-233.

52. van Veen HW, Abee T, Kortstee GJ, Konings WN, Zehnder AJ (1993 Mechanism and energetics of the secondary phosphate transport system of Acinetobacter johnsonii 210A. J Biol Chem 268: 19377-19383.

53. Breeuwer P, Drocourt J, Rombouts FM, Abee T (1996) A novel method for continuous determination of the intracellular ph in bacteria with the internally conjugated fluorescent probe 5 (and 6-)-carboxyfluorescein succinimidyl ester Appl Environ Microbiol 62: 178-183. 